\title{
Safety and effectiveness of a synthetic hemostatic patch for intraoperative soft tissue bleeding
}

This article was published in the following Dove Press journal:

Medical Devices: Evidence and Research

31 March 2015

Number of times this article has been viewed

\author{
Christoph Schuhmacher' \\ Johann Pratschke ${ }^{2}$ \\ Sascha Weiss ${ }^{2}$ \\ Stefan Schneeberger ${ }^{2}$ \\ André L Mihaljevic' \\ Rebekka Schirren' \\ Michael Winkler ${ }^{3}$ \\ Nikos Emmanouilidis ${ }^{3}$ \\ 'Department of Surgery, Klinikum \\ rechts der Isar, Technische Universität \\ München, Munich, Germany; \\ ${ }^{2}$ Department of Visceral, Transplant, \\ and Thoracic Surgery, Medical \\ University of Innsbruck, Innsbruck, \\ Austria; ${ }^{3}$ Department of General, \\ Visceral, and Transplantation Surgery, \\ Hannover Medical School, Hannover, \\ Germany
}

Correspondence: Christoph

Schuhmacher

Medical Faculty TU-Munich, Ismaninger

Str 22, 8I675 Munich, Germany

Tel +49 I5 I2703 I5 I9

Email christoph.schuhmacher@tum.de
Background: Continuous bleeding after using conventional hemostatic methods involving energy, sutures, or clips, is a serious and costly surgical complication. Many topical agents have been developed to promote intraoperative hemostasis, but improvement is needed in both decreasing time to hemostasis and increasing ease of use. Veriset ${ }^{\mathrm{TM}}$ hemostatic patch is CEmarked for controlling bleeding on the liver and in soft tissue. In the current study, we aimed to gather further evidence for the safety and effectiveness of Veriset ${ }^{\mathrm{TM}}$ hemostatic patch in soft tissue bleeding during a variety of surgical procedures.

Methods: Thirty patients scheduled for nonemergency surgery, each with an intraoperative soft tissue bleeding site, were treated with Veriset ${ }^{\mathrm{TM}}$ hemostatic patch. Time to hemostasis was monitored, and adverse events were assessed during the 90 days after surgery.

Results: When Veriset ${ }^{\mathrm{TM}}$ hemostatic patch was used, hemostasis occurred within 5 minutes in 29/30 (96.7\%) subjects and within 1 minute in 21/30 (70.0\%) subjects. No device-related serious adverse events were recorded during the 30 days after surgery, and no reoperations for device-related bleeding complications were performed during the 5 days after surgery.

Conclusions: Veriset ${ }^{\mathrm{TM}}$ hemostatic patch is a safe and effective hemostat for controlling soft tissue bleeding during a variety of surgical procedures.

Keywords: Veriset ${ }^{\mathrm{TM}}$ hemostatic patch, hemostasis, topical hemostat

\section{Introduction}

Uncontrolled intraoperative bleeding is a dangerous complication that can hinder both the surgeon's ability to complete the procedure and the patient's ability to recover. ${ }^{1}$ Blood that remains intra-abdominally after surgery not only increases the extent and severity of postoperative intestinal adhesions, but also serves as a source of intraabdominal infections. ${ }^{2}$ Blood transfusions may become necessary in some cases; these increase the risk of postoperative morbidity and mortality. ${ }^{3,4}$ Furthermore, inadequate hemostasis increases operative time, recovery, and length of hospital stay, and constitutes a considerable economic burden. ${ }^{5}$ Conventional methods of obtaining hemostasis at continuously bleeding sites include repetitive direct cauterization, placement of sutures or clips, and prolonged direct compression, but these methods can impair tissue healing and recovery through the generation of tissue damage, char, and necrosis. ${ }^{6,7}$ Conventional methods might also be impractical or ineffective in regions that are hard to access or in organs and tissues located nearby that can be easily damaged (eg, nerves or the respiratory tract). Therefore, the development of more effective hemostatic agents is critical in order to keep surgical costs down and provide the best safety for patients. 
Many of the commercially available hemostats have been associated with adverse safety. ${ }^{8}$ Hemostats that are based on human- or animal-derived components can lead to virus and disease transmission or elicit anaphylaxis..$^{9-12}$ Additionally, multiple reports have shown granuloma formation and neurological effects associated with the use of some hemostatic agents if not removed. ${ }^{13-19}$ These observations support the need to develop products that effectively achieve hemostasis in a diverse patient population and introduce minimal safety concerns. An ideal hemostatic agent has the potential to decrease the use of blood products in elective and emergency surgery and demonstrates the ability to manage bleeding from both parenchymal and small or inaccessible arterial and venous structures. Such a product would also require adhesive and mechanical strength to withstand the pressure of bleeding. ${ }^{20}$

Veriset ${ }^{\mathrm{TM}}$ hemostatic patch (Covidien, Mansfield, MA, USA) is a recent addition to the plethora of available hemostatic agents. It is composed of an absorbable backing material, oxidized cellulose, and hydrogel components. Veriset ${ }^{\mathrm{TM}}$ hemostatic patch is provided as a ready-to-use patch that is applied polyethylene glycol-side down to the bleeding site. Unlike many other hemostatic agents, which require a dry field prior to application, Veriset ${ }^{\mathrm{TM}}$ hemostatic patch works with physiological fluids to promote hemostasis. Minimal preparation is required for Veriset ${ }^{\mathrm{TM}}$ hemostatic patch, and the device has been shown in preclinical studies to be fully absorbable (Howk, unpublished data, 2015). The device lacks any human- or animal-derived components; thus, it is unlikely to transmit viruses or elicit an immune response.

Veriset $^{\mathrm{TM}}$ hemostatic patch is CE-marked for use in laparoscopic and open procedures involving solid organ or soft tissue bleeding. A previous randomized, controlled clinical study compared Veriset ${ }^{\mathrm{TM}}$ hemostatic patch to TachoSil ${ }^{\circledR}$ (Nycomed Austria GmbH, Linz, Austria) in hepatic procedures. ${ }^{21}$ The number of subjects who achieved hemostasis within 3 minutes was significantly greater among those treated with Veriset ${ }^{\mathrm{TM}}$ hemostatic patch than among those treated with Tachosil ${ }^{\circledR}$. In addition, Veriset ${ }^{\mathrm{TM}}$ hemostatic patch was determined to be both safe and easy to use. The aim of the present study is to provide further evidence for the safety and effectiveness of Veriset ${ }^{\mathrm{TM}}$ hemostatic patch for controlling intraoperative bleeding in soft tissue. The clinical trial registration number for this study is NCT01719172, and it can be found at http:// www.clinicaltrials.gov.

\section{Materials and methods}

\section{Study design}

This study was a prospective, multicenter, single-arm study of Veriset $^{\mathrm{TM}}$ hemostatic patch to assess its safety and effectiveness in obtaining hemostasis in patients undergoing visceral surgical procedures in soft tissue that typically result in considerable sizes of intra-abdominal or intrathoracic connective tissue wound areas. In this study, surgical procedures were included that are likely to lead to hemorrhage in soft tissue areas, which are defined as areas containing tissue that connects, supports, or surrounds other structures of the body or parts of organs. From the perspective of the surgical problem addressed (bleeding from connective tissue in an otherwise highly vulnerable field), inclusion of a variety of procedures was expected to result in a tissue surface that was quite similar across procedures.

During surgery, Veriset ${ }^{\mathrm{TM}}$ hemostatic patch was applied to the target bleeding site (TBS), and its effectiveness was analyzed by capturing the time required for hemostasis to be achieved. Safety was determined by the number of devicerelated serious adverse events (SAEs) during the 30 days after surgery and the incidence of reoperation for device-related bleeding complications during the 5 days after surgery. Subjects were assessed during the procedure and then 24 hours, 7 days, 30 days, and 90 days after the operation. The clinical investigation was conducted according to Good Clinical Practice guidelines and the Declaration of Helsinki, and abided by European and national regulations.

\section{Study participants}

A total of 30 subjects participated in the study. They were selected from three European sites on the basis of protocoldefined inclusion and exclusion criteria. Preoperative inclusion criteria required subjects be $\geq 18$ years of age and already scheduled for nonemergency surgery via an open approach, in which a topical hemostatic agent can be used to control bleeding if conventional methods using energy, sutures, or clips are impractical or unsuccessful. Subjects who were pregnant, breast-feeding, undergoing emergency surgery, scheduled for another planned surgery that could jeopardize study treatment, had a life expectancy of less than 6 months, or had participated in an investigational drug or device study within 30 days of enrollment that would interfere with this study were excluded from eligibility. All eligible subjects provided informed consent and agreed to comply with the treatment and evaluation schedule. Enrolled subjects who did not meet intraoperative criteria were considered screen failures; 
these included subjects who exhibited a local infection at the TBS, whose safety or welfare was determined to be at risk by the investigator, or who did not have a bleeding site of Type 2 (oozing/mild) or Type 3 (moderate) severity (a rating system modeled after classification established by the Bleeding Academic Research Consortium). ${ }^{22}$

\section{Materials}

Veriset ${ }^{\mathrm{TM}}$ hemostatic patch was provided in $5 \times 10 \mathrm{~cm}^{2}$ sheets that could be cut to the appropriate size. Radiopaque gauze (Covidien) was used to assess relative intraoperative bleeding severity prior to the application of Veriset ${ }^{\mathrm{TM}}$ hemostatic patch.

\section{Surgical procedure}

The surgical procedure was performed in accordance with the appropriate practices of the institution at which the procedure occurred. After observing an active bleeding site in soft tissue and determining that conventional methods of obtaining hemostasis were either impractical (an assessment based on the investigator's discretion) or ineffective (an assessment based on a failed attempt to achieve hemostasis with one or more of these methods), the site was selected as the TBS. Veriset $^{\mathrm{TM}}$ hemostatic patch could be cut as necessary to cover the bleeding site with 1-2 cm margins. Multiple patches could be used, if required, with a maximum dosage of $6.43 \mathrm{~cm}^{2} / \mathrm{kg}$. After Veriset ${ }^{\mathrm{TM}}$ hemostatic patch was placed over the TBS, direct pressure was applied. Hemostasis was assessed every 30 seconds until the 5-minute time point, then at 1-minute intervals for minutes 5-10 until hemostasis was achieved. Pressure was maintained in between assessments. Once bleeding had appeared to stop, the TBS was monitored for 1 minute with no pressure to confirm hemostasis. If rebleeding occurred, the assessment was continued at 30-second intervals until 5 minutes, and at 1-minute intervals for minutes 5-10. Additional Veriset ${ }^{\mathrm{TM}}$ hemostatic patch devices were applied if it was noticed that the initial application did not completely cover the TBS, and the timing of the procedure was continued during the subsequent applications. If bleeding persisted after 2 minutes, either continued pressure was maintained or an additional Veriset ${ }^{\mathrm{TM}}$ hemostatic patch was applied.

\section{Assessing intraoperative bleeding with gauze}

Intraoperative bleeding was assessed with gauze prior to the application of Veriset ${ }^{\mathrm{TM}}$ hemostatic patch. Once identified, extraneous fluids were removed. Then, ten gauze pads (40 layers total) were placed on the TBS, and gentle pressure was applied for 3 seconds. After 3 seconds, the gauze was removed, and the number of layers penetrated with blood was recorded. Eligibility was based solely on the discretion of the investigator, regardless of results from the gauze method of assessment, and the TBS was assigned a bleeding severity of Type 2 or Type 3.

\section{Outcome measures}

The primary effectiveness endpoint was the percent success in obtaining hemostasis within 5 minutes after the application of Veriset ${ }^{\mathrm{TM}}$ hemostatic patch. Secondary effectiveness endpoints included the percentage of subjects who achieved hemostasis within 1 minute and the median time required to achieve hemostasis. The primary safety endpoint was the number of device-related SAEs per subject during the 30 days after surgery. The secondary safety endpoint was the incidence of reoperation for device-related bleeding complications during the 5 days after surgery.

\section{Postoperative visits}

To determine adverse events (AEs), subjects were assessed at 24 hours after skin closure by laboratory tests, by testing of vital signs, and by surgical site/infection analyses. A phone call was made 7 days after the surgery to follow up on AEs. Subjects were assessed on the same characteristics 30 days and 90 days after surgery as during the 24-hour postoperative follow-up.

\section{Statistical analysis}

Sample size determination was based on the primary effectiveness endpoint, success in obtaining hemostasis within 5 minutes of Veriset ${ }^{\mathrm{TM}}$ hemostatic patch application. The sample size was calculated by using a one-sided exact test of a binomial proportion versus an objective performance criterion value for $0.5(50 \%)$ to be the proportion of subjects obtaining hemostasis within 5 minutes. The test was performed with a true success proportion of 0.75 , an alpha of 0.025 , and a power of $80 \%$. The required sample size based on these specifications is 30 subjects.

All statistical tests performed were one-sided at the $2.5 \%$ significance level. To analyze the effectiveness of Veriset $^{\mathrm{TM}}$ hemostatic patch in achieving hemostasis, an exact (Clopper-Pearson) 95\% confidence interval for the true success percentage was calculated. A one-sided exact test based on the binomial distribution was performed to test the null hypothesis that the true percentage of subjects who achieved 
hemostasis is less than or equal to $50 \%$; the alternative hypothesis was that the true percentage is greater than $50 \%$. Time to hemostasis was analyzed using the Kaplan-Meier method to estimate the median time to hemostasis. A 95\% Brookmeyer-Crowley confidence interval for the median was computed on the basis of the sign test.

To analyze the safety of Veriset ${ }^{\mathrm{TM}}$ hemostatic patch, a $95 \%$ confidence interval for the mean number of devicerelated SAEs per subject was calculated on the basis of the $t$-distribution. An exact (Clopper-Pearson) 95\% confidence interval for the incidence of reoperation for device-related bleeding complications was calculated. Paired $t$-tests were used to analyze changes in vital signs and other laboratory tests from baseline values. Statistical analyses of data were performed by using SAS Version 9.1 or higher (SAS Institute, Inc., Cary, NC, USA).

\section{Results}

\section{Surgery}

A total of 37 subjects consented to and were enrolled in the study, but seven did not meet preoperative or intraoperative criteria and were considered screen failures (Figure 1).

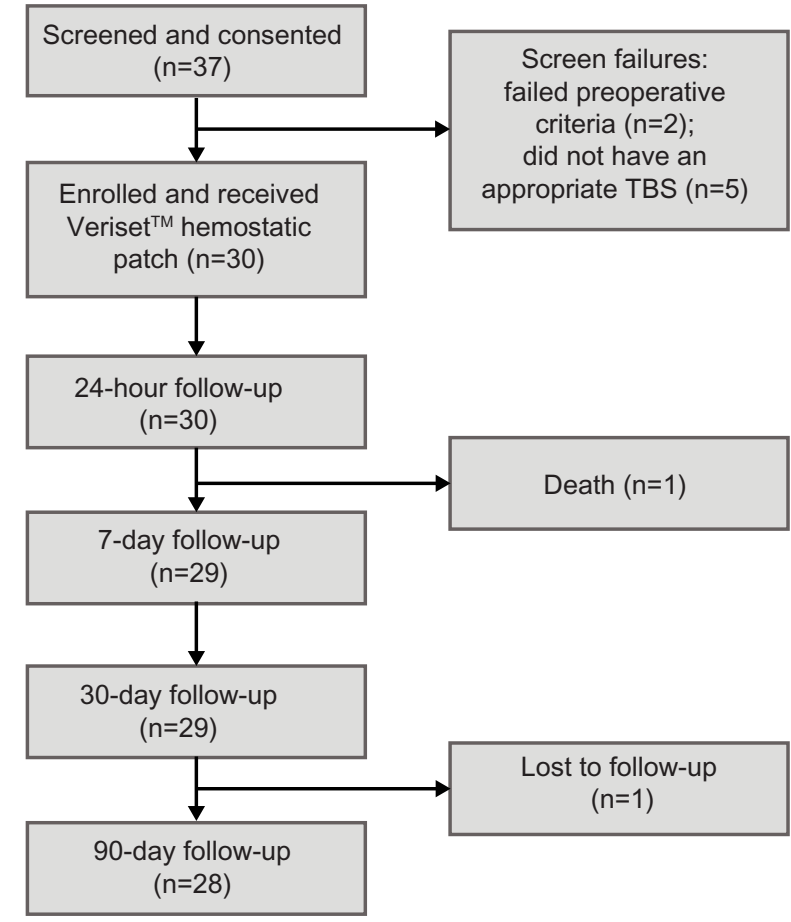

Figure I Subject flow.

Notes: The total number of subjects that were screened and that consented to the study was 37 . Of those, seven were screen failures. The other 30 subjects were treated with Veriset ${ }^{\mathrm{TM}}$ hemostatic patch and assessed according to the procedures in the Material and methods section of this article; however, one subject died (unrelated to use of the device) before the 7-day follow-up and another subject was lost to follow-up before the final 90 -day postoperative assessment.

Abbreviations: $n$, number of subjects; TBS, target bleeding site.
The remaining 30 subjects were treated with Veriset ${ }^{\mathrm{TM}}$ hemostatic patch, but two of the 30 subjects did not complete the study. Of those two subjects, one was lost to follow-up and the other died during the study from embolic complications of a pre-existing atrial thrombus that was unrelated to the test device. Subjects underwent various types of surgical procedures, of which the most common were lymphadenectomy, esophagectomy, colectomy, and pancreatic bed surgery. The mean operation time was 297.2 minutes (range 111-544 minutes). Characterization of the TBS is shown in Table 1. Bleeding occurred in several tissue types and from multiple sources, and the TBS ranged in size from $0.1-200 \mathrm{~cm}^{2}$. Concerning bleeding severity, 22 (73.3\%) subjects had a TBS categorized as Type 2 , and the remaining eight $(26.7 \%)$ were Type 3 . There was a positive correlation between the layers of gauze penetrated with blood and the categorization of bleeding severity determined by the investigators (Table 2).

\section{Effectiveness of Veriset ${ }^{\mathrm{TM}}$ hemostatic patch}

In 26/30 (86.7\%) subjects, conventional methods of obtaining hemostasis were attempted first but were deemed ineffective

Table I Characterization of TBS

\begin{tabular}{|c|c|c|}
\hline Parameter & $\begin{array}{l}\text { Type of } \\
\text { statistic }\end{array}$ & $\begin{array}{l}\text { Veriset }{ }^{\mathrm{TM}} \text { hemostatic } \\
\text { patch }(\mathrm{N}=30)\end{array}$ \\
\hline \multicolumn{3}{|l|}{ Source(s) of bleeding ${ }^{\mathrm{a}}$} \\
\hline Arterial & n (\%) & I (3.3) \\
\hline Venous & n (\%) & $9(30.0)$ \\
\hline Resection/dissection field & $\mathrm{n}(\%)$ & $29(96.7)$ \\
\hline \multicolumn{3}{|l|}{ Tissue type $(\mathrm{s})^{\mathrm{a}}$} \\
\hline Tumor bed & n (\%) & $8(26.7)$ \\
\hline Organ bed & n (\%) & $18(60.0)$ \\
\hline Other & $\mathrm{n}(\%)$ & $8(26.7)$ \\
\hline \multicolumn{3}{|l|}{ Bleeding severity } \\
\hline Type I & $\mathrm{n}(\%)$ & $0(0.0)$ \\
\hline Type 2 & n (\%) & $22(73.3)$ \\
\hline Type 3 & n (\%) & $8(26.7)$ \\
\hline Type 4 & n (\%) & $0(0.0)$ \\
\hline \multirow[t]{5}{*}{ Approximate area of TBS $\left(\mathrm{cm}^{2}\right)$} & $\mathrm{N}$ & 30 \\
\hline & Mean & 20.26 \\
\hline & Median & 6.75 \\
\hline & SD & 38.48 \\
\hline & Range & $0.1-200.0$ \\
\hline \multicolumn{3}{|l|}{ Conventional methods used ${ }^{\mathrm{a}}$} \\
\hline None & n (\%) & $4(13.3)$ \\
\hline Cautery & $\mathrm{n}(\%)$ & $26(86.7)$ \\
\hline Clips & $\mathrm{n}(\%)$ & $9(30.0)$ \\
\hline Staples & $\mathrm{n}(\%)$ & I (3.3) \\
\hline Suture/ligature & n (\%) & $8(26.7)$ \\
\hline
\end{tabular}

Note: aPercentages may sum to more than $100 \%$ since more than one category may apply.

Abbreviations: TBS, target bleeding site; N, total number of subjects in study; $n$, number of subjects; SD, standard deviation. 
Table 2 Bleeding severity and number of layers of gauze penetrated by blood

\begin{tabular}{llll}
\hline Parameter & $\begin{array}{l}\text { Bleeding } \\
\text { severity }\end{array}$ & $\begin{array}{l}\text { Type of } \\
\text { statistic }\end{array}$ & $\begin{array}{l}\text { Veriset }^{\text {TM }} \text { hemostatic } \\
\text { patch }(\mathbf{N}=30)\end{array}$ \\
\hline Layers of gauze that & Type I & $\mathrm{n}$ & 0 \\
blood penetrated & Type 2 & $\mathrm{n}$ & 22 \\
& & Mean & 8.0 \\
& & Median & 8.0 \\
& & SD & 4.4 \\
& & Range & $3-21$ \\
& Type 3 & n & 8 \\
& & Mean & 20.1 \\
& & Median & 16.0 \\
& & SD & 12.0 \\
& & Range & $8-39$ \\
& & & 0 \\
\hline
\end{tabular}

Abbreviations: $\mathrm{N}$, total number of subjects in study; $\mathrm{n}$, number of subjects: SD, standard deviation.

and, in the remaining four subjects, the investigator determined that conventional methods were impractical (Table 1). In all of these subjects, Veriset ${ }^{\mathrm{TM}}$ hemostatic patch was applied to the TBS. Within 1 minute, $70.0 \%$ (21/30) of subjects had achieved hemostasis and, within 5 minutes, $96.7 \%$ (29/30) of subjects had achieved hemostasis (Table 3 ). The median time to hemostasis was 1.0 minute; only three subjects were still bleeding 2.0 minutes after application of the device (Figure 2). The maximum amount of the device required to obtain hemostasis in a single subject was four $5 \times 10 \mathrm{~cm}^{2}$ patches. In $27 / 30$ $(90.0 \%)$ subjects, Veriset ${ }^{\mathrm{TM}}$ hemostatic patch remained in place for the duration of the procedure. In one subject, the investigator opted to remove Veriset ${ }^{\mathrm{TM}}$ hemostatic patch after 2 minutes because hemostasis had not been achieved, and an alternative topical agent was administered. In another subject, hemostasis was achieved with Veriset ${ }^{\mathrm{TM}}$ hemostatic patch but, later in the procedure, it became detached during

Table 3 Effectiveness of Veriset ${ }^{\mathrm{TM}}$ hemostatic patch

\begin{tabular}{|c|c|c|}
\hline Parameter & $\begin{array}{l}\text { Type of } \\
\text { statistic }\end{array}$ & $\begin{array}{l}\text { Veriset }^{\mathrm{TM}} \text { hemostatic } \\
\text { patch }(\mathrm{N}=\mathbf{3 0})\end{array}$ \\
\hline Proportion of subjects & $\mathrm{n} / \mathrm{N}(\%)$ & $29 / 30(96.7)$ \\
\hline achieving hemostasis at & $95 \% \mathrm{Cl}$ for $\%^{\mathrm{a}}$ & (82.8-99.9) \\
\hline TBS within 5 minutes & $P$-value ${ }^{b}$ & $<0.0001$ \\
\hline Proportion of subjects & $\mathrm{n} / \mathrm{N}(\%)$ & $21 / 30(70.0)$ \\
\hline achieving hemostasis at & $95 \% \mathrm{Cl}$ for $\%^{\mathrm{a}}$ & $(50.6-85.3)$ \\
\hline TBS within I minute & $P$-value ${ }^{b}$ & 0.0214 \\
\hline Time to hemostasis for & Median $^{c}$ & 1.0 \\
\hline \multirow[t]{2}{*}{ TBS (minutes) } & $95 \% \mathrm{Cl}$ for & $0.5-1.0$ \\
\hline & Median $^{d}$ & \\
\hline
\end{tabular}

Notes: aClopper-Pearson exact confidence interval; ${ }^{b} P$-value from one-sided exact test based on the binomial distribution to test that the true percent success rate is $\leq 50 \%$ versus the alternative hypothesis that the success rate is $>50 \%$; 'KaplanMeier estimate of the median; ${ }^{\mathrm{B} B r o o k m e y e r-C r o w l e y ~} \mathrm{Cl}$ for the median.

Abbreviations: TBS, target bleeding site; $n$, number of subjects; $N$, total number of subjects in study; $\mathrm{Cl}$, confidence interval. a gastric pull-up maneuver. No tissue damage was observed in these two subjects. In a third subject, Veriset $^{\mathrm{TM}}$ hemostatic patch was later removed when the initial TBS was extracted along with an organ because of a procedural complications unrelated to the use of the device.

\section{Safety of Veriset ${ }^{\mathrm{TM}}$ hemostatic patch}

AEs were monitored at each follow-up, and devicerelatedness was adjudicated by an independent medical monitor. A total of $136 \mathrm{AEs}$ were observed in 23/30 (76.7\%) subjects, and all were typical of the types of surgical procedures performed (Table 4). One subject experienced 25 AEs, and two subjects each experienced 13 AEs; however, most of these were only mild or moderate in severity. Anemia, nausea, impaired healing, and pleural effusion were the only AEs to occur in more than $10 \%$ of subjects. All but one (99.3\%) of the AEs were determined to have no relationship to treatment with Veriset ${ }^{\mathrm{TM}}$ hemostatic patch. In one subject with anemia, the $\mathrm{AE}$ was adjudicated by the independent medical monitor as having an unknown or impossible to determine relationship with the device. There was a total of 20 SAEs in 11/30 (36.7\%) subjects. One subject died before the 7-day follow-up, but the cause, embolism from an atrial thrombus diagnosed prior to surgery, was unrelated to the use of Veriset ${ }^{\mathrm{TM}}$ hemostatic patch. No device-related SAEs were observed for 30 days after the surgery, and no reoperations for device-related bleeding complications were performed within 5 postoperative days. The Data Safety Monitoring Board found no safety issues at the conclusion of the study.

\section{Discussion}

Many different approaches to achieving hemostasis are currently available; these include conventional methods as well as topical agents. ${ }^{8}$ Available methods or devices have advantages and disadvantages that are related to their modes of action or the underlying materials used. Classical surgical techniques, such as sutures, require the presence of mobile adjacent tissue, which will compress the bleeding site by mechanical force but will cause additional trauma to the target area. Electrocautery is effective but causes substantial tissue degradation of an area of the bleeding site and around the focus of application. Topical hemostats have been approved that are either based on coated patch application or that use blood clotting components in a semisolid, fluid-like texture. In certain situations, these existing products exhibit a supportive effect in reaching sufficient hemostasis, but there is still room for improvement in their efficacy, ease of 


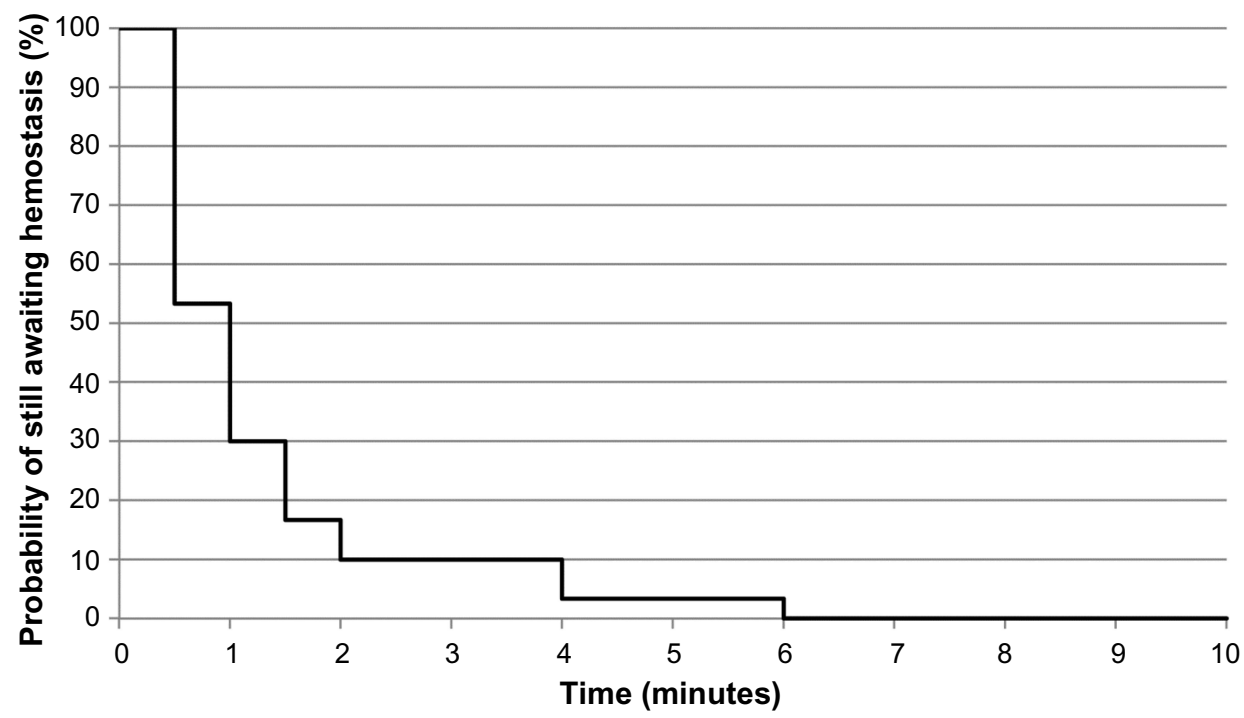

Figure 2 Kaplan-Meier analysis of time to hemostasis.

Notes: After the application of Veriset ${ }^{\mathrm{TM}}$ hemostatic patch, hemostasis was assessed every 30 seconds for the first 5 minutes and every I minute for minutes 5 - I0. All subjects achieved hemostasis within 6.0 minutes, and only three subjects required longer than 2.0 minutes to achieve hemostasis.

use, and adherence to anatomical tissue. Oxidized cellulose, a stand-alone hemostat, has been used for several decades in its regenerated form; however, a recent study showed significant improvement using nonregenerated oxidized cellulose in terms of hemostatic efficiency. ${ }^{23}$ In contrast to these and other available products, Veriset ${ }^{\mathrm{TM}}$ hemostatic patch promotes hemostasis through a dual mode of action that combines the features of two clinically used components: oxidized cellulose and polyethylene glycol hydrogel. Veriset ${ }^{\mathrm{TM}}$ hemostatic patch promotes hemostasis by serving as a tamponade to physically stem blood flow while concentrating platelets and other clotting factors at the bleeding site to accelerate the coagulation cascade.

Table 4 Adverse events

\begin{tabular}{|c|c|c|}
\hline Parameter & $\begin{array}{l}\text { Type of } \\
\text { statistic }\end{array}$ & $\begin{array}{l}\text { Veriset }^{\mathrm{TM}} \text { hemostatic } \\
\text { patch }(\mathrm{N}=30)\end{array}$ \\
\hline Adverse events & n (\%) & $23(76.7)$ \\
\hline Serious adverse events & $\mathrm{n}(\%)$ & II (36.7) \\
\hline Device-related adverse events ${ }^{a}$ & n (\%) & I (3.3) \\
\hline $\begin{array}{l}\text { Unanticipated adverse device } \\
\text { effects }\end{array}$ & $\mathrm{n}(\%)$ & $0(0.0)$ \\
\hline $\begin{array}{l}\text { Device-related serious adverse } \\
\text { events per subject during the } \\
30 \text { days after surgery }\end{array}$ & $\mathrm{n} / \mathrm{N}(\%)$ & $0 / 30(0.0)$ \\
\hline $\begin{array}{l}\text { Reoperation for device-related } \\
\text { bleeding complications during } \\
\text { the } 5 \text { days after surgery }\end{array}$ & $\mathrm{n} / \mathrm{N}(\%)$ & $0 / 30(0.0)$ \\
\hline
\end{tabular}

Note: 'Device-related adverse events are events with a definite, probable, possible, unknown/impossible to determine, or missing relationship to the device.

Abbreviations: $\mathrm{n}$, number of subjects; $\mathrm{N}$, total number of subjects in study.
In this study, a variety of procedure types were performed that were accompanied by soft tissue bleeding from multiple sources. Veriset ${ }^{\mathrm{TM}}$ hemostatic patch stopped blood loss in almost all of these situations, a finding that supports its potential broad range of use. Veriset ${ }^{\mathrm{TM}}$ hemostatic patch was deemed ineffective in only one subject whose bleeding site was determined to have an unusual geometry that did not allow sufficient contact with the device. Multiple applications of Veriset ${ }^{\mathrm{TM}}$ hemostatic patch are feasible to accommodate either especially large bleeding sites or more difficult to treat bleeding sites. Several subjects in this study required multiple applications, but this did not correlate with adverse safety events.

In response to uncontrolled bleeding in the operating room, surgeons typically start with traditionally available methods to achieve hemostasis, such as compression, electrocautery, or direct suture application. ${ }^{24}$ If this initial attempt is unsuccessful, either these methods are used repetitively, or more expensive (and typically more effective) methods are used until bleeding is halted. ${ }^{25}$ Achieving hemostasis in this manner may not always be in the best interest of the patient with regard to both medical and economic outcomes. In some cases, including those in which bleeding occurs on delicate organ tissue or around nerves, it is obvious to the experienced surgeon that certain hemostats are unlikely to halt bleeding without further collateral damage. Opting to use Veriset ${ }^{\mathrm{TM}}$ hemostatic patch as an initial hemostatic agent, instead of attempting more conventional methods first, may save time by allowing quick control of bleeding with little interruption 
to the surgical procedure and minimal risk of complications. In the two cases in which Veriset ${ }^{\mathrm{TM}}$ hemostatic patch either did not adhere or became detached after application, there was no visible tissue damage. This observation suggests that, unlike some conventional hemostatic methods that can cause tissue damage (ie, electrocautery), ${ }^{26,27}$ the use of Veriset ${ }^{\mathrm{TM}}$ hemostatic patch can be attempted with little risk to the patient.

\section{Conclusion}

The results shown here support the use of Veriset ${ }^{\mathrm{TM}}$ hemostatic patch across a variety of surgical procedures that can result in soft tissue bleeding. Additionally, the median time to hemostasis in this study was 1 minute, the same as that observed in the randomized liver study; ${ }^{21}$ this similarity indicates that Veriset ${ }^{\mathrm{TM}}$ hemostatic patch might offer consistent efficacy across multiple tissues. On a practical level, the device exhibits properties that render it convenient and widely applicable. Further studies, particularly in the form of randomized, controlled trials, should be performed in the future to assess such characteristics as safety, efficacy, usability (eg, adhesiveness to tissue, flexibility to underlying structures), and cost-effectiveness, compared to other topical hemostats on the market. While these data would be beneficial to the surgical community, our results combined with the previously published liver results, suggest that Veriset ${ }^{\mathrm{TM}}$ hemostatic patch offers a safe hemostatic method that is effective in many surgical situations.

\section{Acknowledgments}

This study was sponsored and funded by Covidien. The authors thank the study coordinators at each institution and all of the individuals who played a role in designing and facilitating the study. Data analyses were provided by Biostatistical Consulting, Inc. (Burlington, MA, USA). Medical writing and editing support was provided by Caroline Ritchie, $\mathrm{PhD}$ and John Hauschild of Covidien.

\section{Disclosure}

This study was sponsored and funded by Covidien. All authors (or their institutions) received research support from Covidien to conduct this study. Christoph Schuhmacher received funding by Covidien to attend and present data at the European Society of Coloproctology 2013 Annual Meeting and the German Surgical Society 2014 Congress. The authors do not report any additional conflicts of interest in this work.

\section{References}

1. Carson JL, Poses RM, Spence RK, Bonavita G. Severity of anaemia and operative mortality and morbidity. Lancet. 1988;1(8588):727-729.
2. Ryan GB, Grobéty J, Majno G. Postoperative peritoneal adhesions A study of the mechanisms. Am J Pathol. 1971;65(1):117-148.

3. Malone DL, Dunne J, Tracy JK, Putnam AT, Scalea TM, Napolitano LM. Blood transfusion, independent of shock severity, is associated with worse outcome in trauma. J Trauma. 2003;54(5):898-905; discussion 905-907.

4. Moore FA, Moore EE, Sauaia A. Blood transfusion. An independent risk factor for postinjury multiple organ failure. Arch Surg. 1997;132(6): 620-624; discussion 624-625.

5. Shander A. Financial and clinical outcomes associated with surgical bleeding complications. Surgery. 2007;142(4 Suppl):S20-S25.

6. Jensen SS, Yazdi PM, Hjørting-Hansen E, Bosshardt DD, von Arx T. Haemostatic effect and tissue reactions of methods and agents used for haemorrhage control in apical surgery. Int Endod J. 2010;43(1): $57-63$.

7. Soballe PW, Nimbkar NV, Hayward I, Nielsen TB, Drucker WR. Electric cautery lowers the contamination threshold for infection of laparotomies. Am J Surg. 1998;175(4):263-266.

8. Seyednejad H, Imani M, Jamieson T, Seifalian AM. Topical haemostatic agents. Br J Surg. 2008;95(10):1197-1225.

9. Hino M, Ishiko O, Honda KI, et al. Transmission of symptomatic parvovirus B19 infection by fibrin sealant used during surgery. $\mathrm{Br} J$ Haematol. 2000;108(1):194-195.

10. Pope M, Johnston KW. Anaphylaxis after thrombin injection of a femoral pseudoaneurysm: recommendations for prevention. $J$ Vasc Surg. 2000;32(1):190-191.

11. Tadokoro K, Ohtoshi T, Takafuji S, et al. Topical thrombin-induced IgE-mediated anaphylaxis: RAST analysis and skin test studies. J Allergy Clin Immunol. 1991;88(4):620-629.

12. Wai Y, Tsui V, Peng Z, Richardson R, Oreopoulos D, Tarlo SM. Anaphylaxis from topical bovine thrombin (Thrombostat) during haemodialysis and evaluation of sensitization among a dialysis population. Clin Exp Allerg. 2003;33(12):1730-1734.

13. Gao HW, Lin CK, Yu CP, Yu MS, Chen A. Oxidized cellulose (Surgicel) granuloma mimicking a primary ovarian tumor. Int $J$ Gynecol Pathol. 2002;21(4):422-423.

14. Nakajima M, Kamei T, Tomimatu K, Manabe T. An intraperitoneal tumorous mass caused by granulomas of microfibrillar collagen hemostat (Avitene). Arch Pathol Lab Med. 1995;119(12):1161-1163.

15. O'Shaughnessy BA, Schafernak KT, DiPatri AJ Jr, Goldman S, Tomita T. A granulomatous reaction to Avitene mimicking recurrence of a medulloblastoma. Case report. J Neurosurg. 2006;104 (1 Suppl):33-36.

16. Dogan S, Kocaeli H, Doygun M. Oxidised regenerated cellulose as a cause of paraplegia after thoracotomy: case report and review of the literature. Spinal Cord. 2005;43(7):445-447.

17. Henry MC, Tashjian DB, Kasowski H, Duncan C, Moss RL. Postoperative paraplegia secondary to the use of oxidized cellulose (Surgicel). J Pediatr Surg. 2005;40(4):E9-E11.

18. Iwabuchi S, Koike K, Okabe T, Tago S, Murakami T. Iatrogenic paraplegia caused by surgicel used for hemostasis during a thoracotomy: report of a case. Surg Today. 1997;27(10):969-970.

19. John J, Manoj P, Nair SG, Chandrasekharan AP, Satyaprasad V. Paraplegia after thoracotomy: an unusual cause. $J$ Cardiothorac Vasc Anesth. 2006;20(5):696-699.

20. Fischer CP, Bochicchio G, Shen J, Patel B, Batiller J, Hart JC A prospective, randomized, controlled trial of the efficacy and safety of fibrin pad as an adjunct to control soft tissue bleeding during abdominal, retroperitoneal, pelvic, and thoracic surgery. $J$ Am Coll Surg. 2013;217(3):385-393.

21. Öllinger R, Mihaljevic AL, Schuhmacher C, et al. A multicentre, randomized clinical trial comparing the Verise ${ }^{\mathrm{TM}}$ haemostatic patch with fibrin sealant for the management of bleeding during hepatic surgery. HPB. 2013;15(7):548-558.

22. Mehran R, Rao SV, Bhatt DL, et al. Standardized bleeding definitions for cardiovascular clinical trials: a consensus report from the Bleeding Academic Research Consortium. Circulation. 2011;123(23):2736-2747. 
23. Lewis KM, Spazierer D, Urban MD, Lin L, Redl H, Goppelt A. Comparison of regenerated and non-regenerated oxidized cellulose hemostatic agents. Eur Surg. 2013;45:213-220.

24. Samudrala S. Topical hemostatic agents in surgery: a Surgeon's Perspective. AORN J. 2008;88(3):S2-S11.

25. Spotnitz WD, Burks S. Hemostats, sealants, and adhesives III: a new update as well as cost and regulatory considerations for components of the surgical toolbox. Transfusion. 2012;52(10):2243-2255.
26. Lantis JC II, Durville FM, Connolly R, Schwaitzberg SD. Comparison of coagulation modalities in surgery. J Laparoendosc Adv Surg Tech A. 1998;8(6):381-394.

27. Harrell AG, Kercher KW, Heniford BT. Energy sources in laparoscopy. Semin Laparoscop Surg. 2004;11(3):201-209.

Medical Devices: Evidence and Research

Dovepress

\section{Publish your work in this journal}

Medical Devices: Evidence and Research is an international, peerreviewed, open access journal that focuses on the evidence, technology, research, and expert opinion supporting the use and application of medical devices in the diagnosis, treatment and management of clinical conditions and physiological processes. The identification of novel

devices and optimal use of existing devices which will lead to improved clinical outcomes and more effective patient management and safety is a key feature. The manuscript management system is completely online and includes a quick and fair peer-review system. Visit http://www. dovepress.com/testimonials.php to read real quotes from authors.

Submit your manuscript here: http://www.dovepress.com/medical-devices-evidence-and-research-journal 